\title{
Arranjos produtivos locais tecnológicos como estratégia de desenvolvimento regional no estado de Minas Gerais
}

\author{
Daniela Almeida Raposo Torres* \\ Larissa Carla Siqueira**
}

\begin{abstract}
Resumo
Este artigo objetiva avaliar o impacto dos arranjos produtivos locais (APLs) tecnológicos mineiros como instrumentos efetivos de desenvolvimento regional e de superação do relativo atraso econômico entre e intrarregiões. Para tanto, são elencados e analisados indicadores que medem, em termos econômicos, o grau de concentração e competitividade dos APLs tecnológicos mineiros do período entre 2000 e 2010. Em termos sociais, trabalhou-se com o Índice Mineiro de Responsabilidade Social (IMRS) e o Indicador Firjan de Desenvolvimento Municipal (IFDM). Como resultado, indica-se que o desenvolvimento de APLs tecnológicos contribui para a redução do hiato de crescimento entre regiões e, portanto, representam um importante instrumento estratégico de desenvolvimento regional.
\end{abstract}

Palavras-chave: Arranjos produtivos locais. Sistemas de inovações. Desenvolvimento territorial.

* Professora Adjunta no Departamento de Ciências Econômicas da Universidade Federal de São João Del Rei. E-mail: daniraposo@ufsj.edu.br*

** Mestranda no Programa de Pós-Graduação em Administração da Universidade Federal de Lavras. E-mail: larissasiqueira90@yahoo.com.br 


\section{Introdução}

Com o avanço das tecnologias da comunicação e informação, todos têm acesso cada vez mais rápido às diferentes formas de informações. Porém, a difusão do conhecimento não é simples e de fácil acesso, pois é cada vez mais difícil seu acesso devido à importância que esse conhecimento tomou no contexto econômico, dado que o conhecimento é um ativo intangível e estratégico para o desenvolvimento do país (FREEMAN, 1995; NELSON, 1993; LUNDVALL, 1992). Hoje, quem tem conhecimento, tem diferencial.

Nesse âmbito, pode-se definir inovação como a produção de novo conhecimento ou novas combinações de conhecimento existentes transformados em produtos ou processos economicamente significantes. Ademais, a destacada importância da inovação e da difusão tecnológica para o crescimento econômico serve de explicação para as diferenças entre as taxas de crescimento de países e regiões (FAGERBERG, 1994).

Atentos a esse debate, o governo de Minas Gerais, por intermédio da Secretaria de Ciência, Tecnologia e Ensino Superior (Sectes), ${ }^{1}$ definiu a inovação como prioridade da área de ciências, tecnologia e inovação ao entender que tal ação procura agregar valor à economia local. Nesse aspecto, o objetivo do Estado é integrar-se definitivamente à economia do conhecimento como forma de romper as amarras do crescimento, ao promover definitivamente o desenvolvimento regional e setorial (PORTUGAL et al., 2010).

Dentre as ações coordenadas pelo Estado ${ }^{2}$, com o intuito de criar um ambiente institucional favorável ao progresso tecnológico, ${ }^{3}$ destaca-se o apoio ao aprimoramento e ao desenvolvimento dos arranjos produtivos locais (APLs) ${ }^{4}$ de elevado conteúdo tecnológico, definidos em Minas Gerais como os setores de biotecnologia, biocombustíveis, softwares e eletrônicos. O apoio ao desenvolvimento de APLs ganha cada vez mais espaço como importante instrumento estratégico de desenvolvimento regional.

Nesse contexto, este artigo objetiva demonstrar como o desenvolvimento de APLs de elevado conteúdo tecnológico representam um importante instrumento estratégico de desenvolvimento regional, elencando elementos teóricos e empíricos capazes de contribuir para esse debate.

O presente artigo está organizado em cinco seções, incluídas a introdução e a conclusão. Inicialmente, apresenta-se a definição de inovação, elaborada na literatura evolucionária, e sua relação com o crescimento e o desenvolvimento econômico, discutindo a dimensão conceitual de APLs no âmbito da Sectes e sua relação 
com o conceito de sistema de inovação (SI), desenvolvido pela abordagem evolucionária/neoschumpeteriana, ${ }^{5} \mathrm{e}$, a partir da aproximação conceitual desenvolvida, se estabelece as relações causais entre o grau de desenvolvimento dos SIs e/ou APLs e o desenvolvimento regional. Além disso, são elencados e analisados, com dados da Relação Anual de Informações Sociais (Rais) de 2012, para o período entre 2000 e 2010, os indicadores que medem em termos econômicos o grau de concentração (quociente locacional) e competitividade (grau de competitividade setorial) dos setores de biotecnologia, biocombustíveis, softwares e eletrônicos, concentrados principalmente, e respectivamente, na Região Metropolitana de Belo Horizonte, na Microrregião de Uberlândia e na Microrregião de Santa Rita do Sapucaí, todas no estado de Minas Gerais. Em termos sociais, trabalhou-se para as regiões supracitadas com o Índice Mineiro de Responsabilidade Social (IMRS) ${ }^{6}$ e o Indicador Firjan de Desenvolvimento Municipal (IFDM). ${ }^{7}$

\section{Inovação e dinâmica econômica: breves considerações}

A abordagem evolucionária/neoschumpeteriana ${ }^{8}$ contribui com a literatura do crescimento econômico ao lidar com a inovação e o progresso técnico como processos endógenos à dinâmica econômica. ${ }^{9}$ Para tanto, parte-se da consideração de que a inovação é o fenômeno central da dinâmica capitalista, assim como propôs Schumpeter (1982).

Segundo Schumpeter, a inovação, entendida como mudança qualitativa, é a principal responsável pela dinâmica econômica. Assim, essa variável deve ser contemplada nos estudos sobre crescimento econômico. Em Schumpeter, o objetivo principal da firma é o de obter lucro, e esse lucro dar-se-á em virtude da redução dos custos de produção, que resulta do desenvolvimento e/ou descobrimento de um novo insumo básico para a produção, ou da introdução de uma nova mercadoria que garanta às firmas fatias de demanda distintas dos seus concorrentes. Por esse motivo, as firmas estão em constante busca por inovações, pois são elas que garantem a obtenção do lucro. Contudo, o usufruto de novas tecnologias só é plenamente realizado quando as empresas de uma economia conseguem difundir o avanço tecnológico por todo o sistema econômico. Essa difusão da nova tecnologia depende, além da atividade inovativa, da capacidade das firmas de realizar o processo de imitação tecnológica. 
A recompensa econômica associada a uma inovação bem sucedida é, de acordo com Schumpeter, transitória por natureza, desaparece assim que um número suficiente de imitadores a incorpora em seu processo produtivo. O processo de imitação tecnológica que segue a introdução de uma inovação bem sucedida implica na difusão do lucro obtido pelas empresas responsáveis pela introdução da inovação.

Para Schumpeter, a interação entre a inovação e a imitação determina a continuidade do progresso tecnológico, pois a dissipação do lucro extra da empresa inovadora representa um impulso para que ela continue o desenvolvimento de outras inovações a fim de preservar seu rendimento extranormal. Consequentemente, essa competição tecnológica entre as firmas constitui-se em um dos motores do desenvolvimento capitalista, permitindo também explicar os ciclos econômicos. ${ }^{10}$ Então, pela lógica schumpeteriana, o crescimento econômico será tão maior quanto maior for a intensidade das atividades de inovação e imitação tecnológica por parte das firmas de um país ou de uma região. É com base nesses argumentos que a corrente de pensamento evolucionária desenvolve o conceito de sistema de inovação.

\section{Sistema de inovação e APLs tecnológicos mineiros: a construção de uma definição}

O sistema de inovação é um conceito desenvolvido por Freeman, Nelson e Lundvall, em uma obra coletiva de sistematização da abordagem evolucionária, intitulada Techinal change and economic theory, organizada por Dosi et al. (1988).

A razão fundamental para que esses estudos formulem uma teoria sobre os sistemas de inovação relaciona-se ao reconhecimento de que a inovação é um processo interativo. Pela abordagem desenvolvida por Freeman (1988) e Lundvall (1992), o desempenho de inovações da economia apresenta um caráter sistêmico, no sentido de que depende não apenas da capacidade de inovação das empresas individuais, mas também de como elas interagem entre si e com o setor financeiro, os institutos de pesquisa e o governo.

Assim, a capacidade inovativa de um país ou de uma região decorre das relações entre os atores econômicos, políticos e sociais, refletindo condições culturais e institucionais, historicamente definidas. Nesse sentindo, sob uma perspectiva evolucionária, a inovação é entendida como um processo de aprendizado não linear e de múltiplas fontes, derivado de complexas interações em nível local, nacional e mundial entre agentes, firmas e outras organizações voltadas à busca de novos conhecimentos. ${ }^{11}$ 
Esse foco em conhecimento, aprendizado e interatividade deu sustentação à ideia de sistemas de inovação, enfatizando os ambientes nacionais ou locais em que os desenvolvimentos organizacionais e institucionais produzem condições que permitem o crescimento de mecanismos nos quais a inovação e a difusão de tecnologia se baseiam. Então, o desempenho inovativo não depende apenas do desempenho de empresas e organizações de ensino e pesquisa, mas também de como elas interagem entre si e com vários outros atores. Ademais, essa complexa interação de diferentes atores (firmas, universidades, agências governamentais, institutos de pesquisa públicos e privados, instituições financeiras, etc.), isto é, esse arranjo institucional, impulsiona o desenvolvimento tecnológico das nações.

Albuquerque define o sistema de inovação como:

[...] uma construção institucional que impulsiona o progresso tecnológico [...] através da construção de um sistema nacional de inovações, viabiliza-se a realização de fluxos de informação e conhecimento científico e tecnológico necessários ao processo de inovação. Esses arranjos institucionais envolvem firmas, redes de interação entre empresas, agências governamentais, universidades, institutos de pesquisa e laboratório de empresas, bem como a atividade de cientistas e engenheiros: arranjos institucionais que se articulam com o sistema educacional, com o setor industrial e empresarial e com as instituições financeiras, compondo o circuito dos agentes que são responsáveis pela geração, implementação e difusão das inovações tecnológicas(ALBUQUERQUE, 1996a, p. 228). ${ }^{12}$

De outro modo, a Secretaria de Ciência Tecnologia e Ensino Superior define APLs como:

Conjunto de atores econômicos, políticos e sociais, localizados em um mesmo território, desenvolvendo atividades econômicas correlatas e que apresentam vínculos a produção, interação, cooperação e aprendizagem. Amplia e melhora a competitividade e a sustentabilidade dos micro e pequenos negócios de elevado conteúdo tecnológico, estimulando processos, locais de desenvolvimento de forma autossustentável (PORTUGAL et al., 2010, p. 54).

Considere-se que o conceito de APLs, da forma como é definido pela Secretaria de Estado de Ciência, Tecnologia e Ensino Superior (PORTUGAL et al., 2010), aproxima-se sobremaneira da definição evolucionária de um SI. Logo, tanto um SI quanto um APL constituem-se no conjunto de características institucionais, sociais e econômicas que um país ou uma região tem para empreender atividades de inovação e/ou imitação tecnológica.

Nesses sistemas, a performance de inovação de uma economia depende não somente da capacidade de inovação tecnológica das firmas individualmente como também da interação entre elas e com o setor financeiro, os centros de pesquisa e 
com o governo. Essas diferenças variam de acordo com o período histórico e com o país considerado, ou seja, os diversos SIs podem ser descritos a partir das características sociais, econômicas e institucionais que cada país apresenta para desenvolver suas atividades de inovação e difusão tecnológicas.

Dentre as principais características institucionais, econômicas e sociais que compõem um sistema de inovações destaca-se, neste trabalho, o papel do Estado. ${ }^{13}$ $\mathrm{O}$ percentual de gastos em pesquisa e desenvolvimento (P\&D), especialmente em pesquisa básica, espacial e militar, e na promoção de políticas educacionais, industriais e tecnológicas integradas formam exemplos da importância desse setor para o processo de inovação (LUNDVALL, 1992, p. 14; NELSON, 1988, p. 310; FREEMAN, 1995). ${ }^{14}$

Nelson (1988) discute sobre o papel do governo dos Estados Unidos da América, a partir da Segunda Guerra Mundial, no âmbito do SI. Naquele país, os avanços tecnológicos alcançados pelas agências governamentais e militares promovem um efeito de transbordamento (spillovers) sobre a sociedade civil, servindo como fonte de inovações para o setor industrial.

Em sua análise do SI norte-americano, Mowery e Rosenberg (1993 apud FREEMAN, 2005) destacam que os gastos militares no desenvolvimento de novas tecnologias foram fundamentais para a criação de janelas de oportunidade para que setores da indústria civil pudessem avançar tecnologicamente. Os spillovers dos gastos em P\&D do setor militar para o civil reduziu significativamente os custos das empresas privadas na absorção de novas tecnologias, pois os custos do processo de tentativa e erro ficaram, quase que em sua totalidade, a cargo do setor militar. Ou seja, esses grandes estabelecimentos de pesquisa básica, a saber, universidades, governo e empresas privadas, serviram como importantes incubadoras para o desenvolvimento de inovações.

Outro traço característico do SI norte-americano, quanto ao papel do governo, é o reconhecimento da importância de apoiar a educação e a pesquisa universitária em larga escala ${ }^{15}$ bem como o financiamento de pesquisas desenvolvidas dentro do setor produtivo, fatores que promovem um completo efeito de transbordamento entre o setor público e o setor industrial, instigando seu avanço tecnológico. Aspectos elucidados pelas ações dos APLs tecnológicos mineiros, dentre outras ações da Sectes (PORTUGAL et al., 2010).

Em análise do SI japonês, Freeman (1988) também discute a importância do papel do governo, particularmente do Ministry of International Trade and Industry, para o sistema de inovação, ${ }^{16}$ embora, no Japão, o gasto governamental em P\&D seja bem inferior ao nível de gastos realizados pelos norte-americanos, 
especialmente em relação à proporção de gastos com pesquisas militares (NELSON, 1988, p. 310).

Fato também constatado por Freeman (1995, p. 11-12), em estudo comparativo dos SIs do Japão e da URSS na década de 1970, quando a proporção dos gastos com pesquisa militar sobre o total de P\&D da URSS foi maior que o do Japão. ${ }^{17} \mathrm{~A}$ política praticada pelo governo japonês de apoio ao desenvolvimento tecnológico desenvolveu instituições capazes de articular o conhecimento produzido pelas universidades com as indústrias privadas, além de estimular a interação entre firmas de setores diferentes. No Japão, devido à atuação integrada dos laboratórios de $\mathrm{P} \& \mathrm{D}$ das indústrias, os efeitos de learning by interaction eram intensos. A conjugação desses dois fatores (abundante transbordamento entre a pesquisa governamental e a pesquisa civil e fortes interações entre firmas) funcionou como multiplicador dos gastos em P\&D e, associada a outras mudanças sociais e institucionais, permitiu ao país projetar-se na liderança tecnológica.

A constatada aproximação conceitual entre SI, a partir de suas características, e APL permite avançar no debate sobre a contribuição da inovação e da difusão tecnológica para o crescimento econômico. Porém, vale ressaltar que, neste trabalho, a estreita correlação entre as definições de SI e APLs tecnológicos mineiros (PORTUGAL et al., 2010) será utilizada, daqui por diante, no formato SI/APLs.

\section{SI/APLs, competitividade e crescimento econômico}

Nesta seção, procura-se evidenciar a relação entre inovação (SI/APLs), competitividade e crescimento econômico, implicitamente trabalhada em Fagerberg (1988a, 1988b, 1994), Fagerberg e Verspagen (2002) e Cantwell (2005).

O sistema de inovação e os arranjos produtivos locais de um país ou de uma região são importantes determinantes de seu desenvolvimento econômico (FREEMAN, 1995; NELSON, 1993; LUNDVALL, 1992), pois esse sistema determinará a habilidade de um país de criar, adotar e difundir inovações bem como, dessa forma, crescer e se desenvolver.

Contudo, não é, de forma alguma, pressuposto que todo país ou região tenha um SI/APLs avançado. A exemplo disso, os estudos de Nelson (1988, 1993), Freeman (1988) e Kim (2005) relatam e comparam as várias experiências de construção do SI. Esses trabalhos destacam a importância das histórias, das instituições e das culturas dos países e das regiões ${ }^{18}$ para a definição do perfil e da diversidade desses sistemas. 
Segundo Albuquerque, "[...] a diversidade nacional dos sistemas de inovação é função da variedade de articulações entre seus elementos constitutivos” (1996a, p. 230). Os sistemas são diferentes em função: da intensidade e organização do $\mathrm{P} \& \mathrm{D}$, da organização interna das firmas e do relacionamento inter e intrafirmas, do papel das grandes e das pequenas empresas no exercício de inovação e difusão tecnológica, do papel exercido pelo setor público no fomento das atividades de inovação via políticas educacionais, industriais, dentre outras, e financiamento dos gastos com pesquisa, do papel do setor privado na promoção e financiamento dos gastos em $\mathrm{P} \& \mathrm{D}$, dos gastos com pesquisa básica e dos gastos militares, do grau de interação entre ciência e tecnologia, isto é, universidade e indústria, dos objetivos do sistema (disputar a liderança tecnológica ou reduzir a distância entre líderes e seguidoras via catching up ${ }^{19}$ ) (NELSON, 1993; LUNDVALL, 1992; ALBUQUERQUE, 1999).

A diversidade dos sistemas de inovação estabelece a necessidade e a importância da comparabilidade entre eles, uma vez que os estudos de Fagerberg (1988b, 1994) e Albuquerque (1999) apontam para uma forte correlação entre inovação e crescimento econômico. Ou seja, um sistema de inovação, ao contribuir para reduzir o gap tecnológico entre os países e as regiões, serve de estímulo ao crescimento econômico. Em outras palavras, da maneira como está definida pela Sectes (PORTUGAL et al., 2010), a capacidade de uma região de modificar seu sistema econômico depende fundamentalmente da organização de APLs exitosos.

O desenvolvimento desse sistema nacional e/ou de APLs, vital para que o país ou a região realize o processo de catching up, depende, dentre outros fatores, de um significativo esforço de construção de instituições ${ }^{20}$ e de sua integração. De acordo com Dosi et al.:

O desenvolvimento econômico está entrelaçado com mudanças nas instituições que garantem a geração, difusão e exploração do conhecimento tecnológico e com mudanças nas estratégias e organizações das corporações. [...] Sem investimento infraestrutural em educação, treinamento, P\&D e em outras atividades científicas e tecnológicas, muito pouco pode ser conseguido via aquisição de tecnologias importadas (1994, p. 28-29).

Assim, é provável que os países ou as regiões periféricas estejam presos a um círculo vicioso, cuja incapacidade de aprender, em virtude do caráter imaturo do seu sistema de inovação, enquanto que a fronteira tecnológica mundial continua avançando, leva a um empobrecimento contínuo, o que torna o aprendizado ainda mais difícil e limita seu desenvolvimento tanto tecnológico quanto econômico. ${ }^{21}$ Uma forma de essas economias romperem com esse círculo vicioso dar-se-ia pelo amadurecimento de seu SI/APLs. 
Bernardes e Albuquerque (2003) e Bernardes et al. (2006) complementam a análise de comparabilidade entre a maturidade ou não de tais sistemas ao buscar evidências que atestem a relação positiva entre crescimento econômico, produção tecnológica e produção cientifica, no âmbito do SI. Nesses trabalhos, o grau de interação entre ciência e tecnologia - empresas, universidades e instituições -, determinado pelos distintos SIs, assume importante papel no processo de desenvolvimento econômico. Esse argumento aponta para a necessidade de haver investimentos em instituições científicas e tecnológicas para que os países e as regiões iniciem ou consolidem seu processo de catching up. Vale ressaltar, ainda, que o caráter complexo do SI/APLs exige um desenvolvimento de políticas de fomento à ciência e tecnologia coordenadas às demais políticas de crescimento econômico.

Há trabalhos, como o de Pérez e Soete (1988) e o de Dosi et al. (1994), ${ }^{22}$ que destacam a importância da ciência e da tecnologia como precondições fundamentais para o desenvolvimento econômico contemporâneo, especialmente para os países e as regiões periféricas. Segundo Bernardes et al. (2006), os sistemas nacionais e/ou APLs representam um recurso útil para modelar a importância da ciência e da tecnologia como forças motrizes do crescimento econômico.

Nesse sentido, para países e regiões periféricas que tenham interesse em realizar o catching up, a interação entre a ciência e a tecnologia é crucial desde o começo do processo de desenvolvimento. Para esses países e regiões, ciência e tecnologia não devem ser entendidas como luxo, mas como necessidade para o crescimento. Durante as fases iniciais do processo de desenvolvimento, esses espaços limitam-se apenas em absorver os progressos tecnológicos alcançados pelos países ou regiões desenvolvidos ou localizados na fronteira tecnológica. Nesse momento, a forma mais importante para promover o crescimento econômico é por meio da imitação/ difusão tecnológica.

As capacidades de absorção da tecnologia e de aprendizado do processo inovativo dependem de um nível inicial de conhecimento técnico e científico, ou seja, dependem das instituições científicas e tecnológicas (BERNARDES; ALBUQUERQUE, 2003, p. 868-870). É necessário ainda que esses países e/ou regiões apresentem uma articulação entre essas duas dimensões e algumas características sociais que lhes permitam incorporar as novas tecnologias dos países/regiões desenvolvidos. Assim, o caminho para o crescimento econômico prescrito pela teoria evolucionária depende de um sistema de inovação consolidado.

No intuito de reforçar essa afirmação, os resultados de Bernardes e Albuquerque (2003) e Bernardes et al. (2006) ${ }^{23}$ encontram uma forte correlação entre produção científica, produção tecnológica e crescimento econômico no conjunto de países 
e regiões cujo SI é sinalizado como maduro. No conjunto dos países/regiões com SI imaturo, constata-se uma fraca interação entre produção científica, tecnológica e crescimento econômico, o que dificulta ou inviabiliza o seu processo de catch-up.

Ademais, a destacada importância da inovação e da difusão tecnológica para o crescimento econômico serve de explicação para as diferenças entre as taxas de crescimento dos países e das regiões. Segundo Fagerberg (1994), diversos estudos procuram entender porque as taxas de crescimento entre os países e as regiões diferem-se, ressaltando a contribuição da tecnologia para o crescimento econômico.

O estudo do progresso tecnológico como causa principal das diferenças entre as taxas de crescimento dos países e das regiões, por exemplo, via modelos de gap tecnológico ${ }^{24}$ demonstram como as capacidades tecnológicas dos países/regiões têm influência sobre o padrão de competitividade internacional. O termo competitividade, inserido nesse debate, significa a possessão de capacidades/habilidades necessárias para sustentação do crescimento econômico em um ambiente internacional competitivo e seletivo. ${ }^{25}$

Nesse sentido, o esforço de construir instituições para sustentar ou possibilitar o catch-up, nos moldes de um SI e/ou APLs, repercute positivamente sobre a produtividade e a competitividade de uma economia, conforme constatado por Fagerberg (1994), Freeman (1995) Dosi et al. (1994) e Nelson (2005). Logo, a redução de diferenças de produtividade entre os países e as regiões deve-se à redução das diferenças tecnológicas entre eles, viabilizadas pelo desenvolvimento do SI e/ ou APLs. Assim:

A vantagem competitiva é criada e sustentada através de um processo altamente localizado. Diferenças em estruturas econômicas nacionais, valores, culturas, instituições e histórias, contribuem profundamente para o sucesso competitivo. $\mathrm{O}$ papel da nação parece ser tão forte quanto ou mais forte do que nunca. Enquanto a globalização da competição pode fazer parecer o papel da nação menos importante, ao contrário, ele torna-se ainda mais importante. Com poucas barreiras ao comércio para proteger firmas e indústrias domésticas não competitivas, a nação ganha crescente importância porque ela é a fonte de habilidades e de tecnologia que leva à vantagem competitiva (PORTER, 1990 apud FREEMAN 1995, p. 15).

Assim, o SI/APLs é fundamental para o desenvolvimento das atividades inovativas e de sua difusão/imitação, ou seja, ele determina tanto o sucesso competitivo de um país ou de uma região no cenário internacional quanto a sua sustentação nesse ambiente.

Ademais, o processo de desenvolvimento econômico é resultado de duas forças conflitantes: a inovação, que tende a aumentar as diferenças entre países e regiões, e a difusão/imitação, que tende a reduzi-la. $\mathrm{Na}$ verdade, um ambiente disposto a 
reduzir esse gap tecnológico não depende apenas da imitação, via aquisição de tecnologias importadas. Ele depende também de sua performance inovativa, ou seja, da existência de um SI/APLs. Dessa forma, considera-se impossível a substituição do SI/APLs pela importação de tecnologias, tendo em vista o caráter local assumido pela tecnologia. Portanto, a formação de um SI/APLs maduro é precondição para conquista de um espaço na fronteira tecnológica e para o desenvolvimento da competitividade de um país ou de uma região. E, na presença de um SI imaturo, o desenvolvimento dessa competitividade e o crescimento da participação dos países e regiões periféricos (enquadrados nessa categoria) nos mercados externos tornam-se, constantemente, ameaçados.

Os estudos citados atestam uma importante relação entre inovação e crescimento econômico, o que permite explicar as diferenças entre as taxas de crescimento desses locais. Observa-se também os efeitos positivos das atividades tecnológicas sobre a produtividade e a competitividade da economia, variáveis fundamentais para o crescimento econômico e determinante para sua sustentação, devido à possibilidade de expansão da participação no mercado externo. Contudo, esses estudos não trabalham no âmbito do SI e/ou dos APLs, e, de acordo com essa abordagem, o esforço inovativo bem sucedido implica no aumento sustentável da parcela do comércio internacional, ou seja, um SI/APLs maduro implica em maior competitividade e, portanto, maior crescimento.

De outro modo, um SI/APLs imaturo implica em menor competitividade, menor produtividade e menor chance de conquistar a fronteira tecnológica. Logo, países e regiões com SI/APLs imaturos apresentam muitas restrições para realização do processo de catch-up, devido à ausência das principais forças propulsoras do crescimento, não incorporadas nesse sistema de inovação. Portanto, a formação de um SI/APLs é precondição geral para o desenvolvimento econômico (FAGERBERG, 1994) e sua sustentação. Igualmente, os investimentos nas instituições que constituem o SI/APLs são necessários para esquivar países e regiões em desenvolvimento da armadilha do baixo crescimento (BERNARDES; ALBUQUERQUE, 2003).

Em resumo, ressalta-se a importância da construção de SI/APLs eficientes para impulsionar o investimento e, portanto, o crescimento econômico. Com base nessas relações, pode-se atestar que, para romper com o atraso econômico característico de países/regiões periféricos, deve-se promover os SIs dessas regiões, o que justifica a ação de desenvolvimento e aprimoramento dos APLs da maneira definida pela Sectes (PORTUGAL et al., 2010). 


\section{Análise socioeconômica dos APLs tecnológicos mineiros}

Até aqui, preocupou-se em demonstrar como o desenvolvimento de APLs de elevado conteúdo tecnológico representa um importante instrumento estratégico de desenvolvimento regional. Nesse contexto, esta seção tem o intuito de apresentar o estudo de caso dos APLs tecnológicos mineiros dos setores de biotecnologia, eletroeletrônicos e telecomunicações, softwares e bioenergia (biocombustíveis) no período entre 2000 e 2010.

\subsection{O histórico dos APLs dos setores de biotecnologia, biocombustíveis, software e eletrônicos}

Visando ampliar e melhorar a capacidade competitiva de segmentos econômicos de elevado conteúdo tecnológico do estado de Minas Gerais, o governo investe em alguns setores que se destacam no cenário econômico mineiro. Assim, os APLs tecnológicos do estado dividem-se em quatro setores: biotecnologia, eletroeletrônicos e telecomunicações, softwares e bioenergia (biocombustíveis).

Figura 1 - Mapa de distribuição dos APLs tecnológicos mineiros

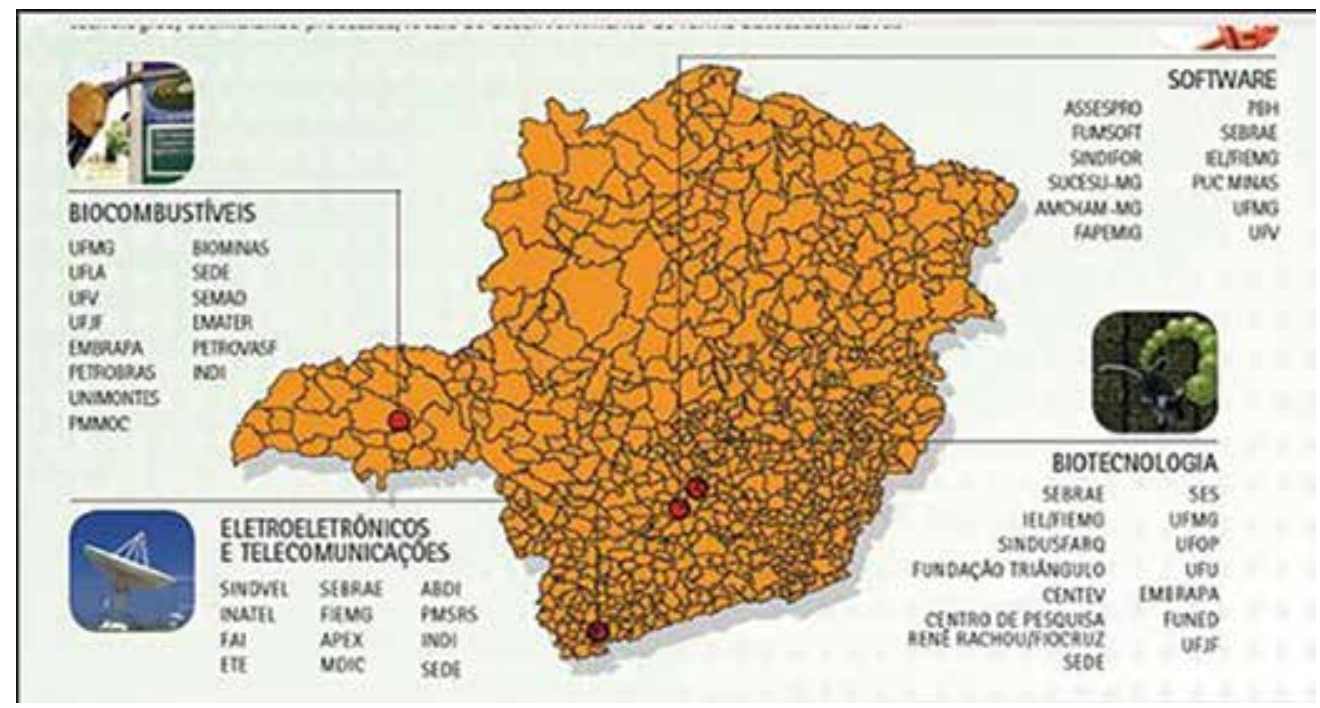

Fonte: Sistema Mineiro de Inovação. Disponível em: <http://www.simi.org.br/biblioteca/exibir/5839> Acesso em: 4 abr. 2012. 
No âmbito tecnológico, esses são os setores estratégicos para os quais Minas Gerais tem vocação ao apresentar algumas vantagens competitivas. Além disso, representam ambientes adequados para investimentos de alto valor agregado, são referência nacional e internacional e integram competências institucionais para induzir o processo de desenvolvimento sustentável de cada segmento.

O setor de biotecnologia, localizado inicialmente em Belo Horizonte, é reconhecido como um dos mais importantes do país, inclusive pelos organismos apoiadores do governo federal, porém, ainda está constituído como um arranjo produtivo do Estado, que o apoia por meio do projeto estruturador, tendo o impulso inicial para seu fortalecimento e reconhecimento. Com a incorporação dos APLs de Viçosa, Triângulo Mineiro e Alto do Paranaíba, o segmento de biotecnologia fortaleceu-se ainda mais.

O setor de eletroeletrônicos, situado no município de Santa Rita do Sapucaí, caracteriza-se por sua organização, pois tem uma liderança bem definida devido ao seu sindicato, o Sindvel, além de ter apoio de renomadas instituições, como o Serviço Brasileiro de Apoio às Micro e Pequenas Empresas (Sebrae), o Instituto Euvaldo Lodi (IEL) e o governo de Minas Gerais, isso é um fator determinante, pois facilita a solidificação do arranjo, fortalece vínculos e promove a competição.

O segmento de desenvolvimento do APL de softwares, situado em Belo Horizonte, tem quatro entidades representativas, as Associações das Empresas Brasileiras de Tecnologia da Informação (ASSESPRO), FUMSOFT, Sindicato das Empresas de Informática de Minas Gerais (SINDINFOR) e Sociedade de Usuários de Informática e Telecomunicações de Minas Gerais (SUCESU), cada uma com objetivos próprios de agregação dos empresários. Por meio de um projeto estruturador elaborado pelo governo mineiro, recebeu o impulso para seu desenvolvimento, assim, logo no início dos trabalhos, um grupo de empresários de Viçosa solicitou o apoio do mesmo projeto, quando foi agregado ao APL.

O setor de bioenergia (biocombustíveis) não se constituía como um APL, somente após um diagnóstico entre empresas e universidades que atuavam no ramo é que se pode desenvolver esse segmento. Com isso, surgiram três cadeias produtivas: o etanol, no Triângulo Mineiro, o biocombustível, no Norte de Minas, e a biomassa, na Região Central do estado (Figura 1).

A rede de apoiadores que dá suporte aos projetos dos APLs mineiros engloba o Sebrae-MG, a Federação das Indústrias do Estado de Minas Gerais, a Federação da Agricultura e Pecuária do Estado de Minas Gerais, o Serviço Nacional de Aprendizagem Industrial, o Serviço Nacional de Aprendizagem Comercial, a Fundação de Amparo à Pesquisa do Estado de Minas Gerais, além de prefeituras, entidades de classe, fornecedores e as secretarias de estado da Ciência e Tecnologia 
e de Desenvolvimento Econômico, entre outras entidades que também dão contribuições variadas para que projetos voltados para os APLs mineiros ganhem competitividade e espaço na economia mineira e nacional.

Desse modo, verifica-se a necessidade de um maior apoio à gestão, por meio de certificações, novos laboratórios e pesquisas, estreitamento de laços com os setores empresarial e governamental, bem como maior interação com a sociedade.

\subsection{Análise do desempenho dos APLs tecnológicos mineiros}

A compreensão da importância do desempenho locacional de um APL pode ser analisada pelo nível de concentração e de competitividade industrial das regiões. Nesse sentido, serão utilizados dois índices, o quociente locacional (QL) e o grau de competitividade setorial (GCS), com dados da Relação Anual de Informações Sociais de 2012, para analisar os APLs mineiros dos setores de biotecnologia, bioenergia, softwares e eletrônicos no período entre 2000 e 2010.

Os filtros aplicados na Rais selecionam trabalhadores com carteira de trabalho assinada em idade ativa (aquela população com dez anos ou mais) de Minas Gerais, da Região Metropolitana de Belo Horizonte, da Microrregião de Uberlândia e da Microrregião de Santa Rita do Sapucaí. A amostra a ser observada é distribuída segundo os ocupados nas atividades de produção de biocombustíveis, dos serviços de tecnologia da informação, da fabricação de eletrodomésticos, de material eletrônico e de aparelhos e equipamentos de comunicação, da fabricação de equipamentos de informática e periféricos e de pesquisa e desenvolvimento, segundo a Classificação Nacional de Atividade Econômica (CNAE). Também se selecionam os dados da Rais que tenham o estabelecimento como unidade de observação.

De acordo com Costa, o quociente locacional "permite identificar e delimitar aglomerações de empresas e, além disso, apontar algumas das características principais da estrutura industrial local" (2010, p. 192). Ele também estabelece uma relação entre a participação do setor no emprego da região e a participação do setor no emprego total do espaço base em questão. De acordo com Barbosa e Torres, "[...] avalia-se a grandeza da concentração e especialização de setores produtivos, ou seja, analisa-se o problema regional em relação às assimetrias regionais" (2010, p. 6). Sua fórmula de cálculo consiste em:

$$
G C S=\frac{E S t_{i j}}{E m p_{i j}} / \frac{E S t_{i b}}{E m p_{i b}}
$$


Sendo $E_{i j}$ o emprego do setor $j$ na microrregião; $E_{i}$ o emprego total da microrregião; $E_{j}$ o emprego do setor $j$ no espaço base; $E$ o emprego total no espaço base.

Por meio do índice obtido, é possível fazer três observações. Se o índice for inferior a 1 (um), a participação do setor na economia da microrregião será proporcionalmente inferior à participação do setor na economia do estado. Isso significa, em primeira instância, que essa microrregião estabelece um fluxo maior de importação de outros municípios do que de exportação dos produtos desse setor. Quando o índice for igual a 1 (um), participação relativa do setor na economia da microrregião será equivalente à participação do setor na economia estadual, o que impede qualquer alusão a uma possível especialização regional. E se o índice for superior a 1 (um), esse setor apresentará uma relativa concentração da atividade comparativamente à economia do estado. Assim, quanto maior for esse índice, maior será o nível de especialização e concentração do setor na microrregião analisada, em comparação com a região base.

O grau de competitividade setorial é o indicador que mede o nível competitivo do espaço em questão, em determinado setor da economia. Sua metodologia de cálculo é determinada pela Equação 2:

$$
G C S=\frac{E S t_{i j}}{E m p_{i j}} / \frac{E S t_{i b}}{E m p_{i b}}
$$

Sendo $\mathrm{GCS}_{i j}$ o indicador que mede a competição do Estado (região ou cidade) em um determinado setor da Classificação Nacional de Atividade Econômica; $E s t ~ i j$ o número de estabelecimentos do setor $i$ na microrregião $j ; E m p_{i j}$ o número de empregados do setor $i$ na microrregião $j ; E s t_{i b}$ o número de estabelecimentos do setor $i$ no estado; $E m p_{i b}$ o número de empregados do setor $i$ no estado.

Segundo Glaese et al. (1991 apud BARBOSA; TORRES, 2010), GCS é uma medida de competição local de determinado setor de atividade. Um alto valor para essa variável, para um setor em uma dada cidade, implica na existência de mais firmas para um dado valor de emprego relativo ao número médio de firmas dividido pelo emprego do setor no estado. Dessa forma, um alto GCS pode ser interpretado como um indicativo de elevada competitividade do setor.

De acordo com a Figura 2, pode-se constatar que o quociente locacional para os setores de biotecnologia, bioenergia, Softwares e eletrônicos, no estado de Minas Gerais, é superior a um por todo o período analisado. Esse índice apresenta média de 1,14, demonstrando o grau de concentração e especialização para os setores. Dessa forma, conclui-se que a constituição dos APLs tecnológicos na Região Metropolitana de Belo Horizonte e nas Microrregiões de Uberlândia e Santa Rita do 
Sapucaí torna-as mais especializadas nesses setores, comparativamente às demais áreas do estado.

Figura 2 - Quociente locacional e grau de competitividade setorial dos setores tecnológicos da

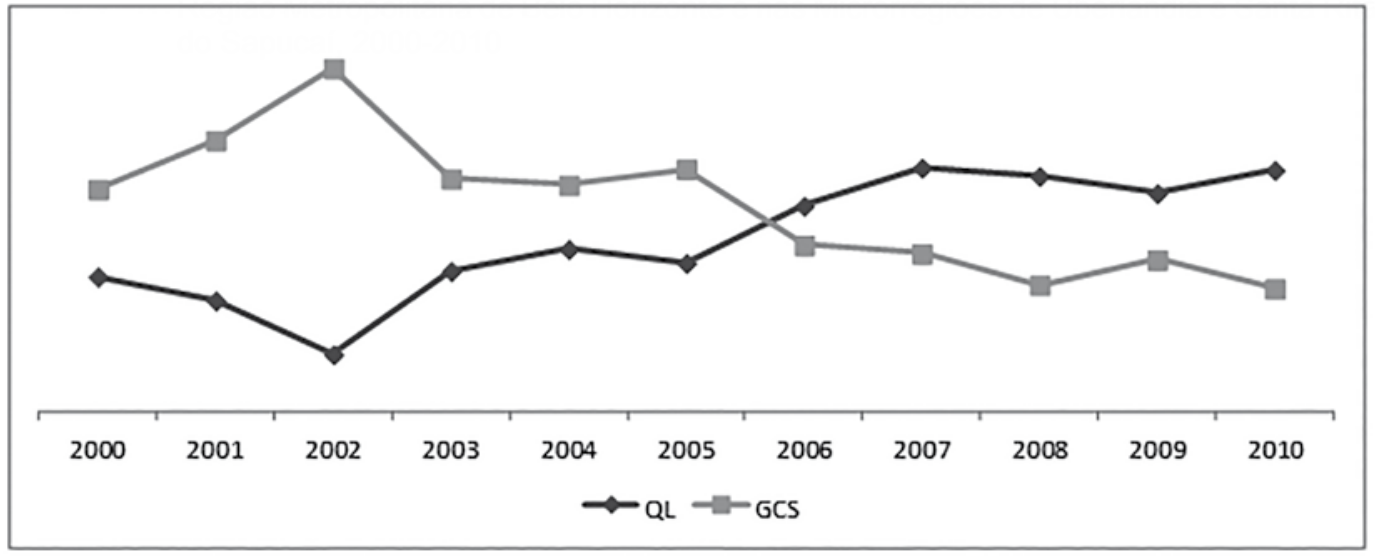

Fonte: elaboração das autoras com base em dados da Rais de 2012.

O GCS da Região Metropolitana de Belo Horizonte e das Microrregiões de Uberlândia e Santa Rita do Sapucaí mostra que essas regiões apresentam a relação entre número de estabelecimentos por número de trabalhadores maior do que a relação no estado de Minas Gerais, apresentando índice médio de 1,18. Assim, esse indicador aponta que nessas regiões há elevada competitividade dos setores tecnológicos. Ademais, o GCS para os setores tecnológicos apresentou um movimento de queda entre 2005 e 2006, passando de 1,25 a 1,11, permanecendo estável a partir de 2006, em uma média de 1,07.

De acordo com a Tabela 1, verifica-se que o número de estabelecimentos dos setores tecnológicos na Região Metropolitana de Belo Horizonte e nas Microrregiões de Uberlândia e Santa Rita do Sapucaí apresenta uma trajetória ascendente praticamente em todo o período analisado, com exceção de 2002 e 2008. Em contraposição ao número de estabelecimentos do setor, há uma redução no número de empregados, com grande destaque para o ano de 2006, com uma queda de 5,52\% em relação ao ano de 2005. Esse resultado explica a ascendência do QL sobre o GCS a partir de 2006 . 
Tabela 1 - Número de empregados e número de estabelecimentos dos setores tecnológicos da Região Metropolitana de Belo Horizonte e das Microrregiões de Uberlândia e de Santa Rita do Sapucaí e do estado, 2000-2010

\begin{tabular}{|c|c|c|c|c|c|c|c|c|c|c|c|}
\hline Variáveis & 2000 & 2001 & 2002 & 2003 & 2004 & 2005 & 2006 & 2007 & 2008 & 2009 & 2010 \\
\hline \multicolumn{12}{|c|}{ Região Metropolitana de Belo Horizonte e Microrregiões de Uberlândia e de Santa Rita do Sapucaí } \\
\hline $\mathrm{N}^{\circ}$ de empregados & 10874 & 10160 & 9696 & 13304 & 15805 & 17998 & 17005 & 23166 & 26449 & 25571 & 28771 \\
\hline $\begin{array}{l}\text { Evolução do } \mathrm{n}^{\circ} \text { de } \\
\text { empregados (\%) }\end{array}$ & & $-6,57$ & $-4,57$ & 37,21 & 18,80 & 13,88 & $-5,52$ & 36,23 & 14,17 & $-3,32$ & 12,51 \\
\hline $\mathrm{N}^{\circ}$ de estabelecimentos & 397 & 462 & 361 & 361 & 386 & 423 & 503 & 580 & 555 & 584 & 606 \\
\hline $\begin{array}{l}\text { Evolução do } n^{\circ} \text { de } \\
\text { estabelecimentos (\%) }\end{array}$ & & 16,37 & $-21,86$ & 0,00 & 6,93 & 9,59 & 18,91 & 15,31 & $-4,31$ & 5,23 & 3,77 \\
\hline \multicolumn{12}{|c|}{ Minas Gerais } \\
\hline $\mathrm{N}^{\circ}$ empregados & 21880 & 21912 & 23550 & 27684 & 31618 & 36866 & 32133 & 40177 & 46163 & 46239 & 50078 \\
\hline $\begin{array}{l}\text { Evolução do } n^{\circ} \text { de } \\
\text { empregados } \%\end{array}$ & & 0,15 & 7,48 & 17,55 & 14,21 & 16,60 & $-12,84$ & 25,03 & 14,90 & 0,16 & 8,30 \\
\hline $\mathrm{N}^{\circ}$ de estabelecimentos. & 522 & 565 & 609 & 609 & 632 & 692 & 856 & 919 & 935 & 975 & 1025 \\
\hline $\begin{array}{l}\text { Evolução do } n^{\circ} \text { de } \\
\text { estabelecimentos } \%\end{array}$ & & 8,24 & 7,79 & 0,00 & 3,78 & 9,49 & 23,70 & 7,36 & 1,74 & 4,28 & 5,13 \\
\hline
\end{tabular}

Fonte: elaborada pelas autoras com base em dados da Rais de 2012.

De toda forma, conclui-se que a Região Metropolitana de Belo Horizonte e as Microrregiões de Uberlândia e de Santa Rita do Sapucaí são tanto especialistas quanto competitivas nos setores tecnológicos, tendo, comparativamente às demais regiões do estado, maior número de estabelecimentos e também maior relação de número de firmas por número de trabalhadores. Assim, os APLs tecnológicos mineiros, foco deste trabalho, apresentam-se especialistas/competitivos, consolidando sua posição-chave nesses setores no estado de Minas Gerais.

\subsection{Desenvolvimento econômico regional dos APLs tecnológicos mineiros}

Para analisar o impacto da constituição de um APL sobre o desenvolvimento econômico regional, optou-se por utilizar dois índices, a saber, o Índice Mineiro de Responsabilidade Social e o Índice Firjan (Federação das Indústrias do Estado do Rio de Janeiro) do Desenvolvimento Municipal, com informações socioeconômicas atuais em nível municipal. Essas bases de dados contêm indicadores sintéticos para as áreas de emprego, renda, educação, saúde, segurança pública, meio ambiente, habitação, cultura, esporte e lazer e finanças públicas municipais, e foram 
escolhidas porque esse conjunto de variáveis consegue expressar o nível de desenvolvimento econômico no âmbito municipal.

Segundo dados fornecidos pela Fundação João Pinheiro (2012), o IMRS é um indicador que expressa o nível de crescimento de cada município:

Definiu-se que o IMRS, um índice desenvolvido para todos os municípios do Estado de Minas Gerais, deveria avaliar a situação desses municípios, contemplando nove dimensões: renda, saúde, educação, demografia, segurança pública, gestão, habitação e meio ambiente, cultura e desporto e lazer. Para cada dimensão, foram selecionados temas relevantes que pudessem retratar a situação existente, a atuação da gestão pública e as iniciativas vinculadas à participação nas decisões. As ações avaliadas foram definidas como aquelas que são (ou deveriam ser) prioridade de programas e de políticas públicas das esferas de governo municipal, estadual e/ou federal. Sendo assim, os diferentes níveis de governo são corresponsáveis por avanços nessas áreas, e o índice retrataria seu sucesso ou sua responsabilidade social conjunta (MINAS GERAIS, 2012).

Em outras palavras, o IMRS avalia a situação de responsabilidade social na gestão dos municípios mineiros por meio das dimensões de renda, saúde, educação, segurança pública, gestão, habitação e meio ambiente, cultura e desporto e lazer. Assim, por ser um índice considerado positivo, por medir a responsabilidade social na gestão municipal, que varia de 0 a 1 , quanto mais perto de 1 for o índice do município, melhor será a sua situação em termos de responsabilidade social e, portanto, melhores serão as condições de o município promover o acesso a bens e serviços que garantam qualidade de vida para a população. É importante destacar que o IMRS é calculado pela junção dessas dimensões na forma de índices sintéticos, sendo que cada tema tem um peso nessa computação. ${ }^{26}$

Como forma de facilitar a análise, o presente estudo adota as mesmas faixas que determinam a qualidade do Índice de Desenvolvimento Humano, ou seja, os valores obtidos entre 0 e 0,499 representam baixo IMRS, valores entre 0,500 a 0,799 correspondem a um IMRS de média qualidade, e valores iguais e/ou superiores a 0,800 correspondem a alto IMRS. ${ }^{27}$

O IFDM, de periodicidade anual, é um recorte municipal de abrangência nacional que considera três áreas de desenvolvimento - emprego/renda, educação e saúde -, e é formado com base em estatísticas oficiais municipalizadas, divulgadas pelos ministérios do Trabalho, Educação e Saúde.$^{28} \mathrm{O}$ índice varia de 0 (mínimo) a 1 (máximo) para classificar o nível de cada localidade. Os critérios de análise estabelecem quatro categorias de desenvolvimento: baixo $(0$ a 0,4$)$, regular $(0,4001$ a 0,6), moderado $(0,6001$ a 0,8$)$ e alto $(0,8001$ a 1$)$.

Cabe ressaltar que para o cálculo da taxa de variação do IMRS, também entendida aqui como taxa de variação do grau de concentração inter-regional, utiliza-se: 
Em que $n$ representa as derivações gerais e específicas do indicador. As variáveis $I M R S_{t}$ e $I M R S_{t-1}$ são dadas pela média aritmética dos valores do índice nos municípios que integram a Região Metropolitana de Belo Horizonte e as Microrregiões de Uberlândia e de Santa Rita do Sapucaí.

Para o cálculo da taxa de variação do grau de concentração intrarregional via desvio padrão do IMRS geral e específico, utiliza-se:

$$
\left.\operatorname{VAR} \operatorname{DVIMRS}_{n}=\left(\left(\operatorname{DVIMRS}_{t} / \operatorname{DVIMRS}_{t-1}\right)-1\right) * 100\right)
$$

Em que $n$ representa as derivações gerais e específicas do indicador. As variáveis $D V I M R S_{t}$ e $D V I M R S_{t-1}$ são dadas pelo desvio padrão dos valores dos índices nos municípios que integram a Região Metropolitana de Belo Horizonte e as Microrregiões de Uberlândia e de Santa Rita do Sapucaí.

A Figura 3 apresenta, para os anos 2000 e 2010, o IMRS específico e geral para a Região Metropolitana de Belo Horizonte e as Microrregiões de Uberlândia e de Santa Rita do Sapucaí, por meio de cores diferentes. Pode-se perceber pelas cores escuras que a região é classificada como médio padrão de responsabilidade social na dimensão geral e específica, exceto para as dimensões meio ambiente e habitação, avaliadas como baixo padrão de responsabilidade social em 2000. Além disso, percebe-se que a dimensão segurança é aquela que mais precisa crescer e se desenvolver para elevar o IMRS, uma vez que em 2000 teve uma avaliação médio padrão de responsabilidade social e, em 2010, uma avaliação de médio padrão de responsabilidade social ainda mais baixa. Saúde e emprego e renda apresentam uma avaliação próxima do alto padrão de desenvolvimento.

Figura 3 - Índice Mineiro de Responsabilidade Social geral e específico para as regiões de APLs tecnológicos mineiros, 2000-2010

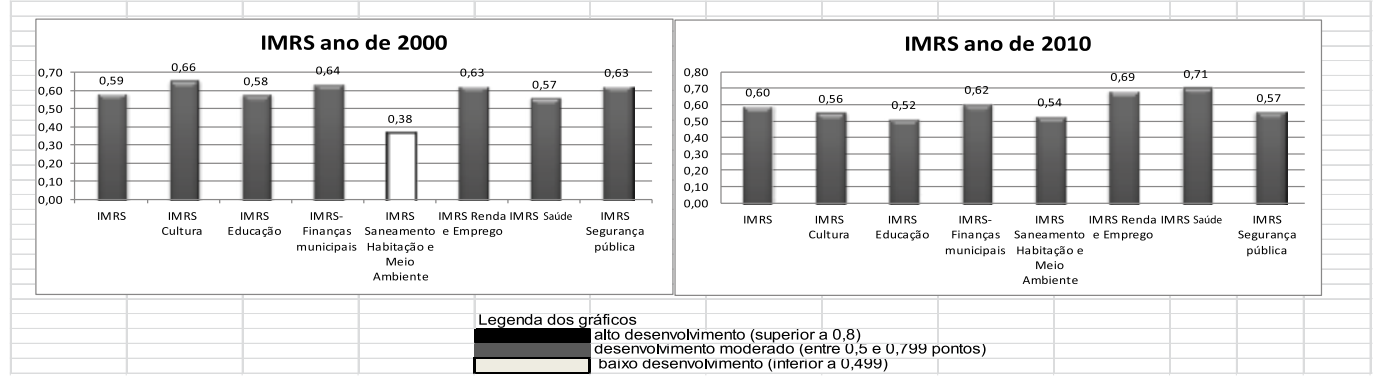

Fonte: elaboração das autoras com base em dados do IMRS 2015. 
A média da Região Metropolitana de Belo Horizonte e das Microrregiões de Uberlândia e de Santa Rita do Sapucaí do IMRS em 2010 foi de 0,60, portanto, $2,06 \%$ maior que a observada em 2000. Além disso, observa-se uma forte expansão das dimensões saúde, saneamento, habitação e meio ambiente e renda/emprego em relação aos anos anteriores e às demais dimensões do indicador, apresentando no caso da saúde um crescimento de $26 \%$, e de saneamento, habitação e meio ambiente de $43 \%$. Pode-se atribuir esses resultados, ou seja, o desenvolvimento de melhores condições para a região promover o acesso a bens e serviços que garantam qualidade de vida para sua população, à constituição do APL tecnológico, dentre outros fatores. Além disso, o estudo apontou um aumento gradual e consistente para a Região Metropolitana de Belo Horizonte e as Microrregiões de Uberlândia e de Santa Rita do Sapucaí com IMRS médio, apontando uma tendência na redução da desigualdade entre os municípios brasileiros (ver Figura 5).

Figura 4 - Variação do IMRS e do desvio padrão geral e específico para as regiões do APLs tecnológicos mineiros, 2000-2010

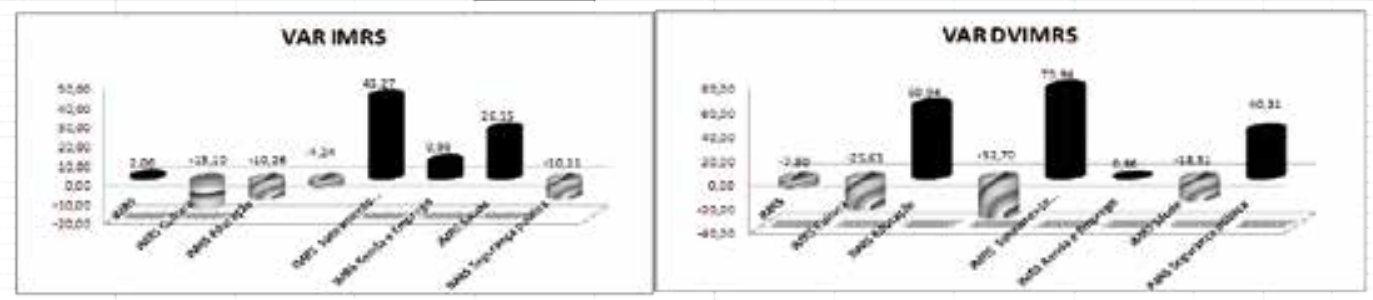

Fonte: elaboração das autoras com base em de dados da IMRS 2015.

Isso porque os resultados da taxa de variação do grau de concentração intrarregional via desvio padrão do IMRS apontam a melhora das condições de acesso da população dos municípios que compõem as regiões dos APLs tecnológicos mineiros no âmbito geral, da saúde, da cultura e da gestão das finanças públicas. Ao registrar uma taxa de, respectivamente, $-7,8 \%,-18 \%,-26 \%,-33 \%$, sinalizam que a diferença entre o acesso desses requisitos nos municípios, que era grande em 2000 , reduziu no ano de 2010, em outras palavras, o desenvolvimento da região nesses requisitos contemplou, em média, todos os municípios que a compõem.

Em compensação, outras variáveis mostram gargalos na economia intrarregional, a exemplo de segurança, educação, meio ambiente e habitação, renda e emprego, que, apesar do constatado desenvolvimento na região, não contemplou todos os municípios constituintes, uma vez que as taxas positivas de variação sinalizam que a dispersão entre a geração de segurança, educação, meio ambiente e habitação, renda e emprego ampliou-se intrarregionalmente entre 2000 e 2010. Vale 
ressaltar o retrocesso da dimensão segurança, retraindo-se em $-10,11 \%$ entre os anos de 2000 e 2010, e o aumento de $40 \%$ no grau de concentração intrarregional.

A Figura 5 ilustra o IFDM da Região Metropolitana de Belo Horizonte e das Microrregiões de Uberlândia e de Santa Rita do Sapucaí no período entre 2000 e 2011. Percebe-se que a maioria dos índices atribui à região um desenvolvimento socioeconômico moderado. A média do IFDM da região Metropolitana de Belo Horizonte e das Microrregiões de Uberlândia e de Santa Rita do Sapucaí em 2011 foi de 0,84 , portanto, $23 \%$ maior do que a observada em 2000 . Vale ressaltar que em todos os municípios que integram essa região observa-se uma melhora no IFDM geral no período entre 2000 e 2011 (FIRJAN , 2012). Os dados retratam o impacto da constituição dos APLs tecnológicos, dentre outros fatores, no desenvolvimento desses municípios. Isso porque o estudo apontou um aumento gradual e consistente da região dos APLs tecnológicos com IFDM moderado, revelando uma tendência na redução da desigualdade entre os municípios brasileiros (ver Figura 5).

Figura 5 - Índice Firjan de Desenvolvimento Municipal geral e específico para as regiões dos APLs tecnológicos mineiros, 2000-2011

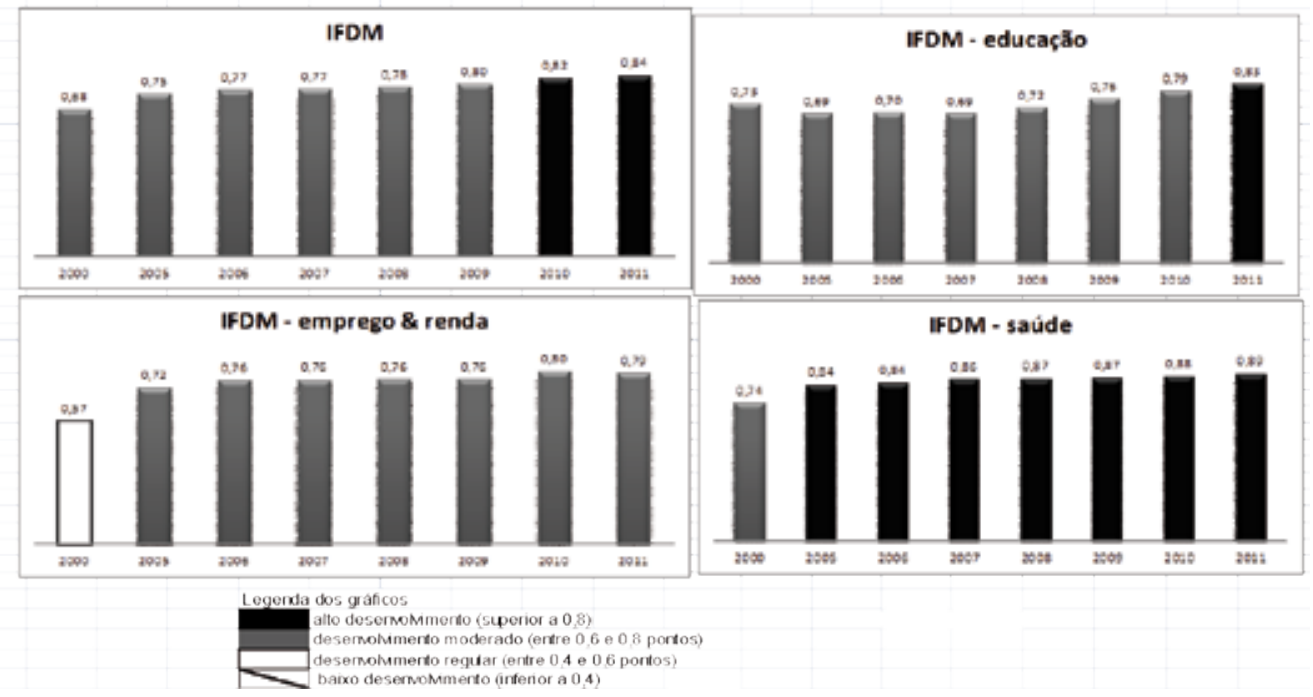

Fonte: elaboração das autoras com base em dados da Firjan (2012).

Os IFDMs saúde, emprego e renda e educação registraram expansão em relação aos anos anteriores, apresentando, no caso do primeiro, um IFDM de alto desenvolvimento crescente e, para o segundo, um IFDM com índices moderados de desenvolvimento ascendente, resultado da melhora nesses índices específicos em todos os municípios constituintes região dos APLs tecnológicos (FIRJAN, 2012). 
A média da Região Metropolitana de Belo Horizonte e das Microrregiões de Uberlândia e Santa Rita do Sapucaí do IFDM saúde em 2011 foi de 0,89, 21\% maior do que a observada em 2000, enquanto que a média do IFDM educação em 2011 foi de 0,83 , logo, $13 \%$ maior do que a observada em 2000. O IFDM emprego e renda também registrou expansão de 38\% em 2011 em relação ao ano de 2000, porém, com esse resultado permanece no nível de desenvolvimento moderado (ver Figura 6). Vale ressaltar que os municípios que compõem a região dos APLS tecnológicos apresentaram melhora em todos seus índices de desenvolvimento, haja vista os resultados da taxa de variação entre o ano de 2011 e 2000 dados na Figura 6), confirmando com a tendência na redução da desigualdade em termos de desenvolvimento em relação aos demais municípios brasileiros.

Figura 6 - Variação do IFDM geral e específico para as regiões dos APLs tecnológicos mineiros, 2000-2011

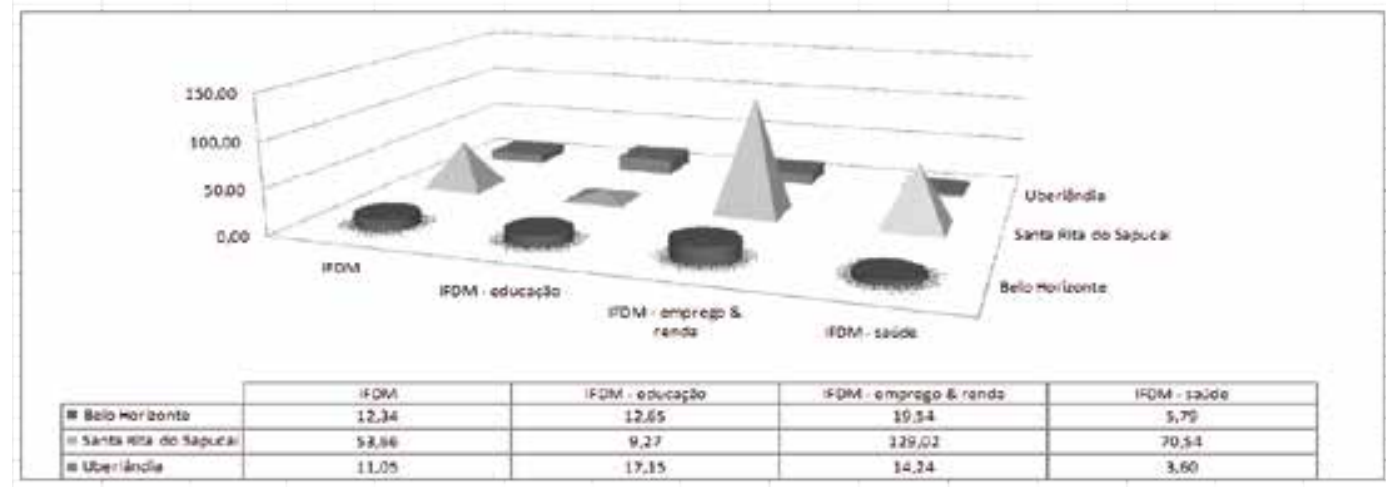

Fonte: elaboração das autoras com base em dados da Firjan (2012).

Nota: VAR IFDM geral e específico estimada via Equação 3.

De maneira geral, esta análise mostrou que muito foi modificado no decorrer de onze anos, uma vez que os municípios integrantes dos APLs tecnológicos mineiros tiveram seu perfil socioeconômico alterado. Essas mudanças contribuíram para o crescimento econômico da região devido, principalmente, ao desenvolvimento regional nas áreas de saúde, educação, cultura e esportes. Esse resultado também contribuiu para a redução das desigualdades entre os demais municípios mineiros e brasileiros, ou seja, reduziu o hiato de crescimento entre as demais regiões. De outro modo, verifica-se que, apesar dessa evolução, ainda existem sérios problemas na economia desses municípios que entravam seu desenvolvimento, pois identifica-se gargalos nas áreas de segurança pública, meio ambiente e habitação, emprego e renda. 


\section{Considerações finais}

Este artigo procurou demonstrar como o desenvolvimento de APLs de elevado conteúdo tecnológico representam um importante instrumento estratégico de desenvolvimento regional.

Assim sendo, conclui-se que a definição de APLs dada pela Sectes do estado de Minas Gerais aproxima-se do conceito de SI segundo a abordagem neoschumpeteriana (evolucionária). Tal aproximação permite demonstrar a importância desses sistemas para impulsionar o investimento, o crescimento e o desenvolvimento econômico regional de economias periféricas. Fica demonstrado que a constituição de SI/APLs maduros permite às economias em desenvolvimento romperem com o circuito de causação circular ao qual estão sujeitos seu crescimento e desenvolvimento.

Ademais, no que se refere ao grau de atratividade e competitividade, medido pelo QL e pelo GCS, conclui-se que a Região Metropolitana de Belo Horizonte e as Microrregiões de Uberlândia e de Santa Rita do Sapucaí são especialistas nos setores de biotecnologia, bioenergia, softwares e eletrônicos.

Ademais, no caso do GCS, os resultados encontrados podem ser interpretados apenas como um indicativo de elevada competitividade desses setores comparativamente ao estado. Vale ressaltar que observa-se um aumento gradual e consistente do GCS para todos os setores no período entre 2000 e 2009. Assim, os APLs mineiros de elevado conteúdo tecnológico, foco deste trabalho, apresentam-se como especialistas/competitivos, consolidando sua posição-chave nesse setor no estado.

Para analisar o impacto da constituição de um APL sobre o desenvolvimento econômico regional, optou-se pelos índices IMRS e IFDM, com informações socioeconômicas atuais em nível municipal para o período entre 2000 e 2009. Essas bases de dados contêm indicadores sintéticos para as áreas de emprego, renda, educação, saúde, segurança pública, meio ambiente, habitação, cultura, esporte e lazer e finanças públicas municipais, e foram escolhidas porque esse conjunto de variáveis consegue expressar o nível de desenvolvimento econômico no âmbito municipal.

De maneira geral, os resultados da análise dos índices demonstraram que muito foi alterado em nove anos, uma vez que os municípios mineiros integrantes dos APLs de biotecnologia, bioenergia, softwares e eletrônicos tiveram seu perfil socioeconômico modificado. Essas mudanças contribuíram para o crescimento econômico regional devido, principalmente, ao desenvolvimento regional nas áreas de saúde, educação, emprego e renda, meio ambiente e finanças públicas. Esse resultado também contribuiu para a redução do hiato de crescimento entre as demais regiões do estado, representando um importante instrumento estratégico de desenvolvimento regional. Contudo, ainda existem obstáculos ao seu desenvolvimento nas áreas de segurança pública, emprego e renda. 


\title{
Local productive arrangements technology while a regional development strategy in the state of Minas Gerais
}

\begin{abstract}
The paper aims to assess the impact of Local Productive Arrangements (Arranjos Produtivos Locais - APLs) technological of Minas Gerais as effective instruments of regional development and get over the relative economic delay between and within regions. For this are listed and analyzed for the period between 2000 and 2010, indicators that measure in economic terms the degree of concentration and competitiveness technology clusters of Minas Gerais. In social terms worked with the Mining Social Responsibility Index (Indice Mineiro de Responsabilidade Social - IMRS) and the FIRJAN indicator of Municipal Development (Índice de Desenvolvimento Municipal - IFDM). As result can to realize that the development of APLs technology contribute to reduce the growth gap between regions and therefore represent an important strategic tool for regional development.
\end{abstract}

Keywords: Local clusters. Innovation systems. Regional development.

\section{Tecnología arreglos productivos locales como una estrategia de desarrollo regional en el estado de Minas Gerais}

\section{Resumen}

El presentetrabajo pretendeevaluar elimpactodeArreglos Productivos Locales(APLs)mineros tecnológicos como instrumentos eficaces de desarrollo regional y para superar el atraso económico relativo entre y dentro de las regiones. Por tanto se enumeran y se analizaron para el período comprendido entre 2000 y 2010 , los indicadores que miden en términos económicos, el grado de concentración y la competitividad de los clusters de tecnología minera. En términos sociales trabajaron con el Índice de Responsabilidad Social Minería (IMRS) y el Indicador de Firjan de Desarrollo Municipal (IFDM). Como resultado, podemos ver que el desarrollo de la tecnología de APL ayuda a reducir la brecha de crecimiento entre las regiones y por lo tanto representan una herramienta estratégica importante para el desarrollo regional.

Palabras clave: Arreglos productivos locales. Sistemas de innovación. Desarrollo territorial. 


\section{Notas}

1 Segundo Dos Santos, "[...] o Estado de Minas Gerais foi pioneiro na criação de uma secretaria voltada para o desenvolvimento cientifico e tecnológico" (2010, p. 71).

2 Para mais detalhes sobre outras ações governamentais para desenvolvimento da inovação do Estado de Minas Gerais, ver Portugal et al., (2010),.

3 O projeto estruturador dos APLs é parte de uma gama de projetos ligados ao Sistema Mineiro de Inovação (Simi). O Simi foi constituído em 2006 com a responsabilidade de coordenar o ambiente institucional voltado para a inovação (PORTUGAL et al., 2010).

4 Costa (2010) discute diversas formas de conceituar um APL. Segundo o autor, "[...] de forma mais genérica um APL pode ser entendido como um grupo de agentes 'orquestrados' por um grau de institucionalização explícito ou implícito ao aglomerado que buscam como finalidade, harmonia, interação e cooperação, não esquecendo, vale repisar, que estes elementos ocorrem num ambiente competitivo, no qual há sujeitos com distintos graus de poder e com projetos territoriais diversos e muitas vezes antagônicos" (2010, p. 127). O conceito de APL neste artigo deriva-se da Sectes segundo Portugal et al. (2010).

5 Ver em Nelson e Winter (1982) sobre o desenvolvimento tanto dos antecedentes quanto das premissas básicas da abordagem evolucionária.

6 O Índice Mineiro de Responsabilidade Social é calculado pela Fundação João Pinheiro e encontra-se disponível para consulta no endereço eletrônico <http://www.fjp.gov.br/index.php/indicadores-sociais/-imrs-indice-mineiro-de-responsabilidade-social>. Para mais detalhes, inclusive metodológicos, ver Minas Gerais (2012).

7 O Índice Firjan do Desenvolvimento Municipal e calculado pela Federação das Indústrias do Estado do Rio de Janeiro e encontra-se disponível para consulta nos endereços eletrônicos <http://www.firjan.org. $\mathrm{br} / \mathrm{IFDM} />$ ou $<\mathrm{http}: / / \mathrm{www}$.ipeadata.gov.br/>. Para mais detalhes, inclusive metodológicos, ver Federação das Indústrias do Estado do Rio de Janeiro (2012).

8 Em Nelson e Winter (1982), verificar o desenvolvimento tanto dos antecedentes quanto das premissas básicas da abordagem evolucionária.

9 O trabalho de Nelson e Winter (2005) apresenta críticas ao modelo neoclássico de crescimento e discute a necessidade de uma abordagem evolucionária na teoria do crescimento.

10 Para mais detalhes sobre os ciclos econômicos, ver Schumpeter (1982).

11 Ver em Nelson e Winter (1982) o desenvolvimento tanto dos antecedentes quanto das premissas básicas da abordagem evolucionária.

12 Lundvall (1992) propõe um conceito amplo e restrito de SI, o primeiro corresponde à definição exposta, e o segundo conceito, restrito, envolve apenas as instituições formais de ciência e tecnologia (FREEMAN, 1992, p. 173).

13 Para um estudo aprofundado sobre as principias características institucionais de um SI, ver Raposo (2009).

14 Freeman (1995, p. 15-18) sugere que List, em 1841, com seu sistema nacional de economia política, teria antecipado muitos aspectos do debate contemporâneo sobre NSI, entre eles, enfatiza o papel do governo na coordenação e aplicação de políticas de longo prazo para a indústria e a economia. Ele reconhece ainda a interdependência de importação de tecnologias estrangeiras e desenvolvimento técnico doméstico, pois os países poderiam adquirir a tecnologia e em função de sua capacidade de aprendizado tecnológico poderiam crescer mais.

15 Segundo Freeman (2005, p. 65), o apoio do governo federal e da maior parte dos governos estaduais à educação e pesquisa universitária podem ser considerados como um dos mais importantes, se não o mais importante, aspecto do NSI dos EUA.

16 Freeman também discute outros aspectos que tornam o NSI japonês único. Além do importante papel do governo, especialmente na figura do Ministry of International Trade and Industry, considera o papel das firmas, especialmente dos Keiretsu, o papel das inovações educacionais e sociais. Para mais detalhes ver Freeman (1992, cap. 16).

17 Freeman (1995, p. 11-12) resume as principais diferenças entre o NSI do Japão e da URSS na década de 1970.

18 Muitos autores trabalham com a questão da inovação, imitação/difusão, sob forte influência histórica e enfatizando outros fatores econômicos, sociais e institucionais para explicar as diferenças entre as taxas de crescimento dos países, a exemplo de Veblen (1915), Gerschenkron (1962), Abramovitz $(1979,1986)$ e Maddison (1979, 1982, 1991). 
19 Entende-se como um processo de catching up a redução do gap tecnológico entre um país líder e um grupo de países seguidores. Ver Gerschenkron (1962) e Abramovitz (1986).

20 Argumento que pode ser atribuído a Gerschenkron (1962). Segundo o autor, a absorção de novas tecnologias envolve um significativo esforço de construção de instituições.

21 A caracterização de um SI como maduro ou imaturo estaria diretamente relacionada ao grau de desenvolvimento econômico de um país. Os sistemas de inovação que capacitam os países a se localizarem na fronteira tecnológica são denominados maduros. Os países cujos sistemas nacionais de inovação não foram concluídos são compreendidos como imaturos (ALBUQUERQUE, 1999).

22 Para mais referências, ver Bernardes e Albuquerque (2003).

23 O artigo de Bernardes et al. (2006) contribui empiricamente ao debate da relação entre inovação e crescimento ao constatar o papel da ciência e da tecnologia para a riqueza das nações.

24 Esses modelos de gap tecnológico, desenvolvidos em Fagerberg (1988b), Fagerberg J, Verspagen (2002), entre outros, representam uma aplicação da teoria de desenvolvimento econômico schumpeteriana. Esses modelos analisam o crescimento econômico como um processo de desequilíbrio, caracterizado pela relação conflitante entre duas forças: a inovação, que tende a aumentar as diferenças econômicas e tecnológicas entre os países, e a imitação ou difusão, que tende a reduzir essas diferenças.

25 Para mais detalhes sobre o termo, ver Cantwell (2005).

26 Segundo dados da Fundação João Pinheiro (2011), a média ponderada dos subíndices referentes a sete dimensões cujos pesos estão entre parênteses são: educação $(20 \%)$, saúde $(20 \%)$ m segurança pública (10\%), meio ambiente e habitação (10\%), cultura, esporte e lazer (10\%), renda e emprego (15\%) e finanças municipais (15\%). Esse índice, assim como seus subíndices, foi calculado para os anos de 2000, 2002, 2004 e 2006. Para 2008, a metodologia de cálculo foi alterada.

27 O Índice de Desenvolvimento Humano é elaborado pelo Programa das Nações Unidas para o Desenvolvimento. Para mais detalhes ver Instituto de Pesquisa Econômica Aplicada, disponível em: <http://www. ipeadata.gov.br/>.

28 Segundo dados da Firjan (2012), em 2011, os dados oficiais mais recentes disponíveis são de 2009. O estudo começou em 2008, comparando os anos de 2005 e 2000, e permite determinar com precisão se a melhora ocorrida em determinado município foi decorrente de medidas políticas ou apenas o reflexo da queda de outro município. Para mais detalhes, ver Federação das Indústrias do Estado do Rio de Janeiro. $2011,2012$.

\section{Referências}

ABRAMOVITZ, M. Catching up forging ahead and falling behind. Journal of Economic History, Wilmington, v. 46, n. 2, p. 386-406, June 1986.

Rapid growth potential and its realization: the experience of capitalist economics in the postwar period. In: MALINVAUD, E. (Ed.) Economic growth and resources. London: Macmillan, 1979. v. 1. p. 1-30.

ALBUQUERQUE, E. M. National systems of innovation and Non-OECD countries: notes about a rudimentary and tentative "typology". Brazilian Journal of Political Economy, São Paulo, v. 19, n. 4, p. 35-52, Oct./Dec. 1999.

Notas sobre a contribuição de Kenneth Arrow para a fundamentação teórica dos sistemas nacionais de inovações. Revista Brasileira de Economia, Rio de Janeiro, v. 50, n. 2, p. 227242, abr./jun. 1996a.

Sistema nacional de inovação no Brasil: uma análise introdutória a partir de dados disponíveis sobre a ciência e a tecnologia. Revista de Economia Política, São Paulo, v. 16, n. 3, p. 56-72, jul./set. $1996 \mathrm{~b}$.

BARBOSA, Reginaldo Avelar; TORRES, Daniela Almeida Raposo. Empresa motriz e desenvolvimento regional: análise dos impactos da Iveco na cidade de Sete Lagoas-MG. In: SEMINÁRIO SOBRE A ECONOMIA MINEIRA, 14, Diamantina. Anais... Belo Horizonte: Universidade Federal de Minas Gerais. Disponível em: <http://EconPapers.repec.org/RePEc:cdp:diam10:069>. Acesso em: 8 abr. 2012. 
BERNARDES, A. T. et al. Modeling economic growth fuelled by science and technology. Belo Horizonte: UFMG/Cedeplar, 2006. (Texto para discussão, 294).

BRASIL. Ministério do Trabalho e Previdência Social. Relação Anual de Informações Sociais. 2012. Disponível em: <http://acesso.mte.gov.br/portal-pdet/home/>. Acesso em: 8 abr. 2012.

CANTWELL, J. Innovation and Competitiveness. In: FAGERBERG, J.; MOWERY, D. C.; NELSON, R. R. The Oxford handbook of innovation. Oxford: Oxford University, 2005. 656 p. p. 543-567.

COSTA, J. M. Arranjos produtivos locais, políticas públicas e desenvolvimento regional. Brasília: Mais Gráfica, 2010.

DOS SANTOS, Fabiana Borges Teixeira. Ciência, tecnologia e inovação em Minas Gerais: desafios e oportunidades. In: OLIVEIRA, F. A.; SIQUEIRA, W. B (Org.). As muitas Minas: ensaios sobre a economia mineira. Belo Horizonte: Conselho Regional de Economia, 2010. 248 p. p. 49-88.

DOSI, G.; FREEMAN, C.; FABIANI, S. The process of economic development: introducing some stylised facts and theories on technologies, firms and institutions. Industrial and Corporate Change, Oxford, v. 3, n. 1, p. 1-45, Feb. 1994.

DOSI, G. et al. Technical change and economic theory. London: Pinter, 1988. 646 p.

FAGERBERG, J. International competitiveness. Economic Journal, Cambridge, v. 98, n. 391, p. 355-374, 1988a.

. Technology and international differences in growth rates. Journal of Economic Literature, Nashville, v. 32, n. 4, p. 1147-1175, Sept. 1994.

. Why growth rates differ. In: DOSI, G. et al. Technical change and economic theory. London: Pinter, 1988b. p. 432-457.

FAGERBERG J.; VERSPAGEN , B. Technology-gaps, innovation-diffusion and transformation: an evolutionary interpretation. Research Policy, Amsterdam, v. 31, n. 8/9, p. 1291-1304, Dec. 2002 .

FEDERAÇÃO DAS INDÚSTRIAS DO ESTADO DO RIO DE JANEIRO. Índice Firjan de Desenvolvimento Municipal. 2012 . Disponível em: <http://www.firjan.org.br/IFDM/>. Acesso em: 8 abr. 2012.

FREEMAN, C. Formal Scientific and technical institutions in the national system of innovation. In: LUNDVALL, A.-B. (Ed.). National systems of innovation: towards a theory of innovation and interactive learning. London: Pinter, 1992. p. 169-187.

Japan: a new national system of innovation? In: DOSI, G. et al. Technical change and economic theory. London: Pinter, 1988. p. 330-348.

. The national system of innovation in historical perspective. Cambridge Journal of Economics, London, v. 19, n. 1, p. 5-24, Feb. 1995.

Um pouso forçado para a "nova economia"? A tecnologia da informação e o sistema nacional de inovação dos Estados Unidos. In: LASTRES, H. M. M.; CASSIOLATO, J. E.; ARROIO, A. (Org.). Conhecimento, sistemas de inovação e desenvolvimento. Rio de Janeiro: UFRJ, 2005. Cap. 2. p. 51-81.

GERSCHENKRON, A. Economic backwardness in historical perspective. Cambridge, USA: Belknap, 1962. 456 p. 
KIM, L. Tecnologia, aprendizado e inovação: as experiências das economias de industrialização recente. Campinas, SP: Unicamp, 2005. 503 p.

LUNDVALL, A.-B. (Ed.). National systems of innovation: towards a theory of innovation and interactive learning. London: Pinter, 1992. 342 p.

Innovation as an interactive process: from user-producer interaction to the national system of innovation. In: DOSI, G. et al. Technical change and economic theory. London: Pinter, 1988. p. 349-369.

MADDISON, A. Dynamics forces in capitalist development. New York: Oxford, 1991.

. Long run dynamics of productivity growth. Banca Naz. Lavoro Quarterly Rev., Rome, v. 32, n. 128, p. 3-43, mar. 1979.

. Phases of capitalist development. New York: Oxford, 1982.

MINAS GERAIS. Fundação João Pinheiro. Índice Mineiro de Responsabilidade Social. 2012. Disponível em: <http://www.datagerais.mg.gov.br/index.php/industria>. Acesso em: 8 abr. 2012.

NELSON, R. Institutions supporting technical change in the United States. In: DOSI, G. et al. Technical change and economic theory. London: Pinter, 1988. p. 312-329.

sity, 1993.

(Ed.). National innovation systems: a comparative analysis. New York: Oxford Univer-

NELSON, R.; WINTER, S. An evolutionary theory of economic change. Cambridge: Harvard University, 1982. $437 \mathrm{p}$.

. Uma teoria evolucionária da mudança econômica. Campinas: Unicamp, 2005. 631 p.

PÉREZ, C.; SOETE, L. Catching up in technology: entry barriers and windows of opportunity. In: DOSI, G. et al. (Ed.). Technical change and economictheory. London: Pinter, 1988. p. 458-459.

PORTUGAL, A. D. et al. Minas Avança na economia do conhecimento. Inovação: uma face do estado para resultado. Belo Horizonte: Secretaria de Estado de Ciência, Tecnologia e Ensino Superior, 2010. $320 \mathrm{p}$.

RAPOSO, D. A. T. Liquidez internacional e crescimento econômico: uma análise pós-keynesiana da experiência mundial. 2009. Tese (Doutorado em Economia) - Universidade Federal de Minas Gerais, Belo Horizonte, 2009.

SCHUMPETER, J. A. Teoria do desenvolvimento econômico. São Paulo: Abril Cultural, 1982. (Os Economistas, 1).

VEBLEN, T. Imperial Germany and the industrial revolution. New York: Macmillan, 1915. 